
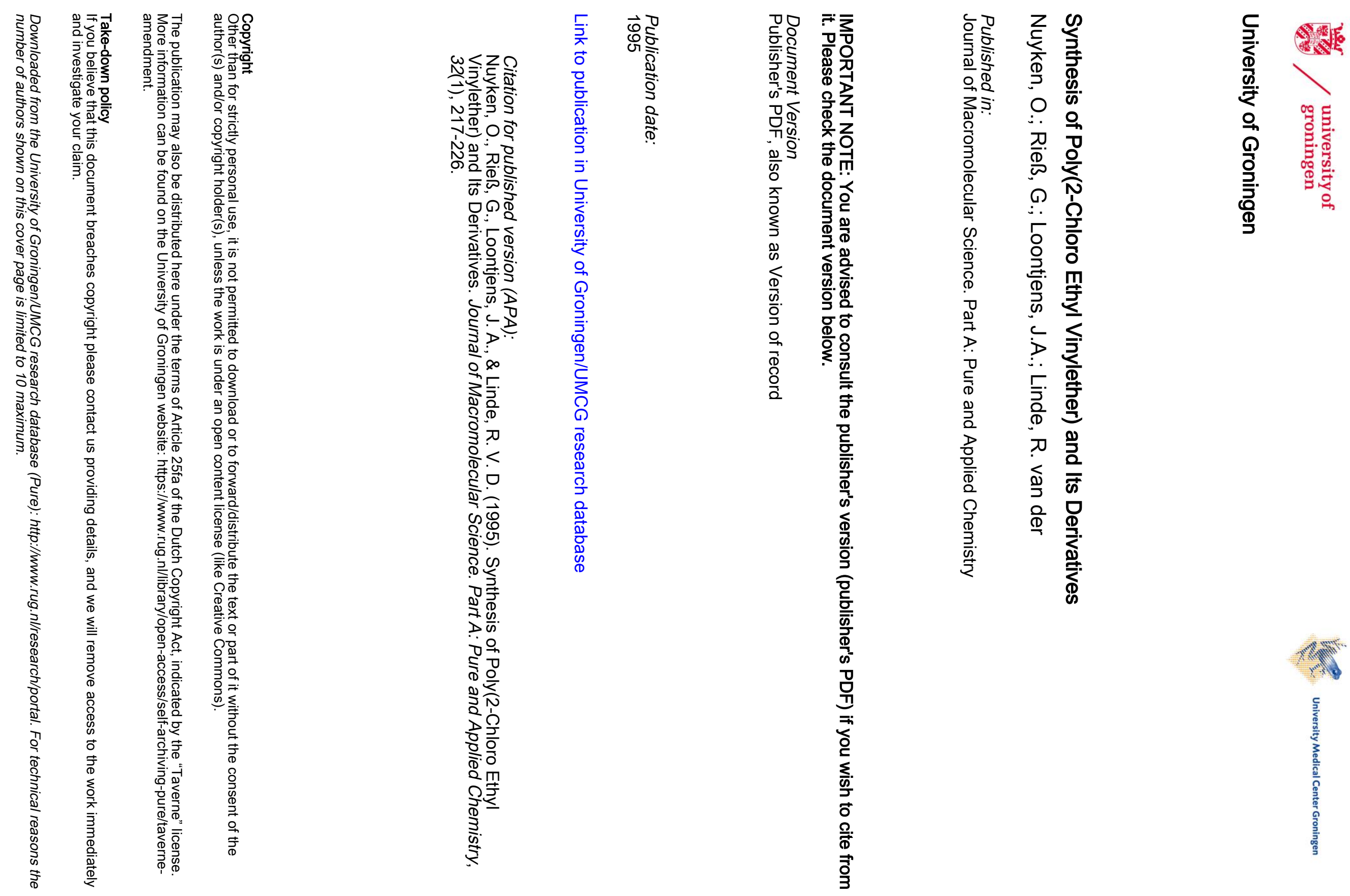

응

.

芯 䍘

क

\

ㄷ. 욤

응 임

끔

ङ

은 몬

离.

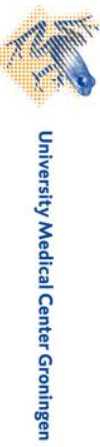




\title{
SYNTHESIS OF POLY(2-CHLORO ETHYL VINYLETHER) AND ITS DERIVATIVES
}

\author{
o. Nuyken*, G. Ries \\ Lehrstuhl für Makromolekulare Stoffe \\ Technische Universität München \\ Lichtenbergstr. 4, D-85747 Garching, Germany \\ J.A. Loontjens \\ DSM, Research, PO box 18 \\ NL-6160 MD Geleen, The Netherlands \\ $R$. van der Linde \\ DSM Resin b.V., P.O.Box 615 \\ NL-8000 AP, Zwolle, The Netherlands
}

\begin{abstract}
The cationic polymerization of 2-chloro ethyl vinylether (CEVE) is initiated by 1-iodo-1-(2-methylpropyloxy) ethane/( $\mathrm{n}-\mathrm{Bu})_{4} \mathrm{NClO}_{4}$. The monomer is consumed following first order kinetics. Molar masses are controlled by the ratio [M]:[I]. A rather narrow molar mass distribution is obtained. These observations and the linear conversion-molar mass relationship indicate the living nature of the CEVE polymerization. Poly(CEVE) was converted into poly(2-(1-pyrrolidonyl)-1-ethylvinylether) by the complete nucleophilic substitution of chlorine by the anion of pyrrolidone.
\end{abstract}

\section{INTRODUCTION}

Cationic polymerization of 2-chloro ethyl vinylether (CEVE) has already been studied in some detail. Important work was 
rublished by Higashimura et al. on the initiation of CEVE by $H I / I_{2}{ }^{1}$ and by Deffieux et al. on the initiation by II $/ \mathrm{ZnI}_{2}{ }^{2)}$ and 1-iodo-1-(2-methylpropyloxy) ethane $\mathrm{ZnCl}_{2} / \mathrm{ZnI}_{2}$ respectively $y^{3,4)}$.

In this contribution we will describe the polymerization () CEVE initiated by 1-iodo-1-(2-methylpropyloxy)ethane/(n-Bu) ${ }_{4} \mathrm{NClO}_{4}$ according to the following scheme:<smiles>CC(C)COC(C)I</smiles>

\section{1. $\mathrm{CH}_{2}=\mathrm{CH}-\mathrm{OCH}_{2} \mathrm{CH}_{2} \mathrm{Cl}$}
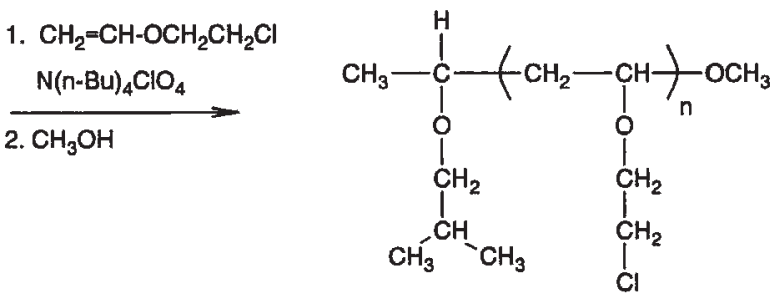

Inother objective of this study is to synthesize a rolyvinylether with pyrrolidone as polar side groups.

\section{RESULTS AND DISCUSSION}

I'olymerization of $\mathrm{CEVE}$ was carried out in $\mathrm{CH}_{2} \mathrm{Cl}_{2}$ at $-10^{\circ} \mathrm{C}$ ky adding successively a solution of 1-iodo-1-(2-methylfropyloxy)ethane in $n$-hexane and a solution of in-Bu) ${ }_{4} \mathrm{NClO}_{4}$. The monomer conversion was followed by gas chromatography with toluene as internal standard. Typical experimental data are given in TABLE 1.

T'he plot of $\ln (1-\mathrm{C})$ against the time(FIG. 1) is a straight line which indicates, that monomer consumption follows the first order kinetics.

The polymerization rate of CEVE is remarkable slower than that of e.g. isobutylvinylether (IBVE) 1,2,6). However, the initiation is fast and only the chain growing is a slow reaction, which one can conclude from FIG. 3 . From earlier experiments with this initiating systems we know that the actual ion concentration is very $10 w^{7}$. 
TABLE 1:

Polymerization of CEVE initiated by 1-iodo-1-(2-methylpropyl-oxy) ethane (I) / (n-Bu) ${ }_{4} \mathrm{NClO}_{4}(\mathrm{~A})$. $[C E V E]_{0}=0,99 \mathrm{~mol} I^{-1},[I]_{0}=0,02 \mathrm{~mol} I^{-1}$

[A] $=0,02 \mathrm{~mol} 1^{-1}, \quad \mathrm{~T}=-10^{\circ} \mathrm{C}$

\begin{tabular}{ccc} 
time & conversion $\left(\frac{\circ}{6}\right)$ & $\ln (1-\mathrm{C})$ \\
\hline $10 \mathrm{~min}$ & 4,1 & $-0,042$ \\
$75 \mathrm{~min}$ & 9,5 & $-0,198$ \\
$6 \mathrm{~h}$ & 26,8 & $-0,312$ \\
$19 \mathrm{~h}$ & 58,0 & $-0,868$ \\
$27 \mathrm{~h}$ & 71,5 & $-1,255$ \\
$44 \mathrm{~h}$ & 88,0 & $-2,120$ \\
\hline
\end{tabular}

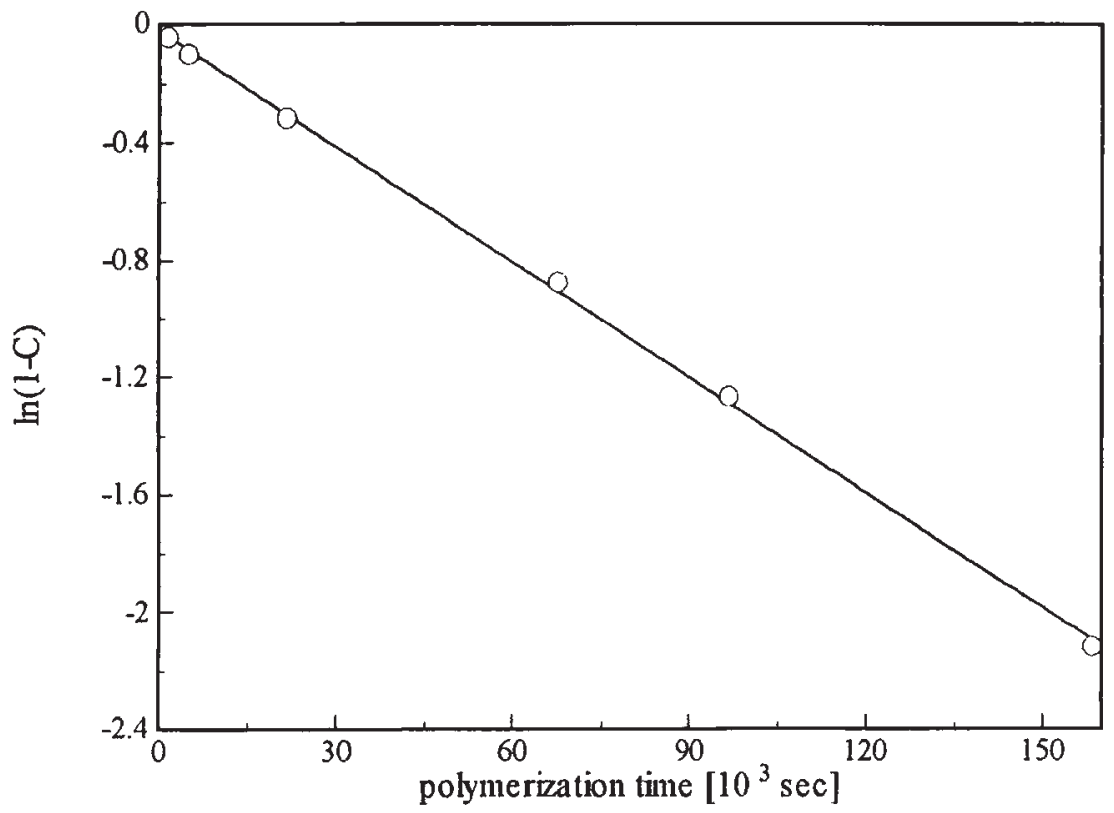

FIG. 1: Polymerization of CEVE with 1-iodo-1-(2-methylpropyloxy) ethane/ $(\mathrm{n}-\mathrm{Bu}){ }_{4} \mathrm{NClO}_{4}$ in $\mathrm{CH}_{2} \mathrm{Cl}_{2}$ at $-10^{\circ} \mathrm{C}$. 


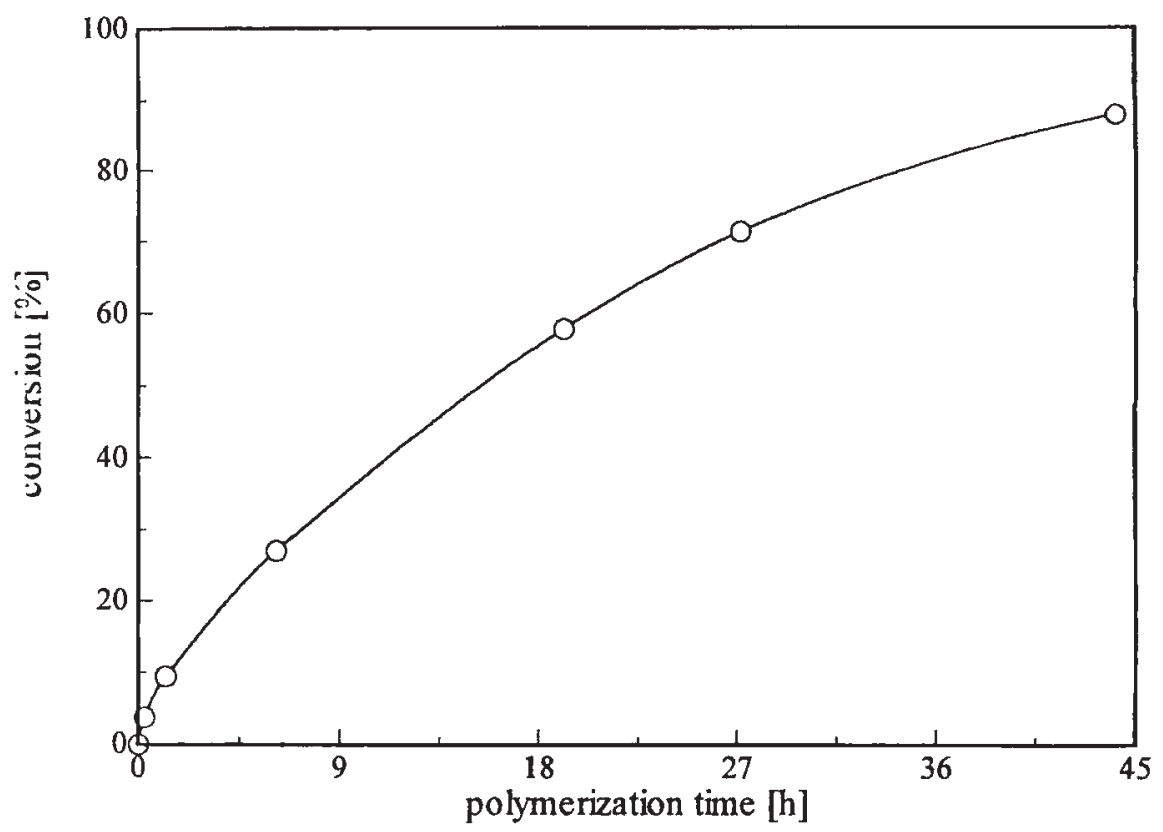

FIG. 2: Polymerization of CEVE with 1-iodo-1-(2-methylpropyloxy) ethane/ $(\mathrm{n}-\mathrm{Bu})_{4} \mathrm{NClO}_{4}$ in $\mathrm{CH}_{2} \mathrm{Cl}_{2}$ at $-10^{\circ} \mathrm{C}$.

Therefore we assume that reversible termination plays an important role in this type of polymerization.

The agreement of calculated and observed molar masses is not perfect (TABLE 2). FIG. 4 shows clearly a linear molar mass-conversion relationship, which points to a living system.

\section{REACTION OF POLY (CEVE) WITH PYRROLIDONE}

Since 2-(1-pyrrolidonyl)ethyl vinylether (PEVE) could not be polymerized with the initiating systems applied for $\mathrm{CEVE}^{6)}$ we have tried to synthesize poly(PEVE) by 


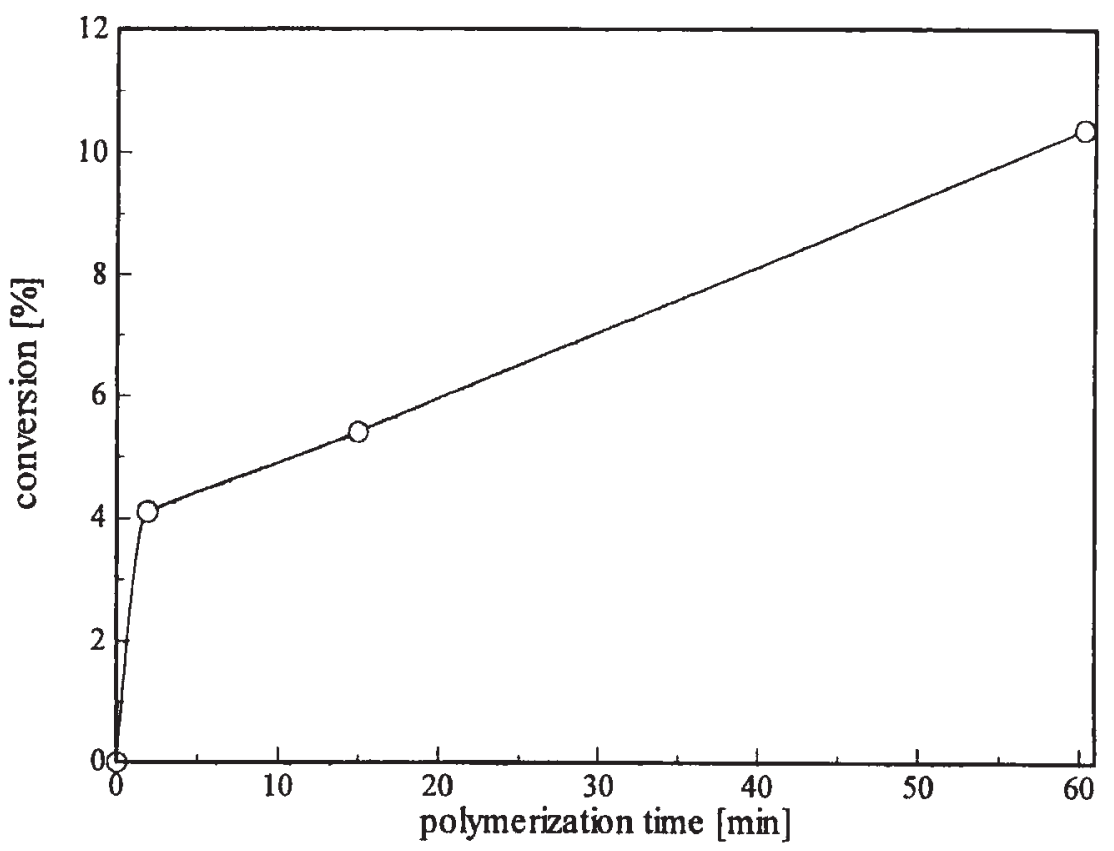

FIG. 3: Polymerization of CEVE with 1-iodo-1-(2-methylpropyloxy) ethane/(n-Bu) ${ }_{4} \mathrm{NClO}_{4}$ in $\mathrm{CH}_{2} \mathrm{Cl}_{2}$ at $-10^{\circ} \mathrm{C}$, first $60 \mathrm{~min}$.

TABLE 2 :

Polymerization of CEVE, initiated by 1-iodo-1-(2methylpropyloxy) ethane/(n-Bu) ${ }_{4} \mathrm{NClO}_{4}$ in $\mathrm{CH}_{2} \mathrm{Cl}_{2}$ at $-17^{\circ} \mathrm{C}$; $[\mathrm{M}]_{0}=1,0 \mathrm{~mol} 1^{-1},[I]_{0}=0,03 \mathrm{~mol} 1^{-1},[A]=0,023 \mathrm{~mol} \mathrm{I}^{-1}$

\begin{tabular}{ccccc}
$t$ & $C \div$ & $M_{n}(\text { GPC })^{1)}$ & $M_{n}$ (calc.) & $M_{w} / M_{n}$ \\
\hline $5 \mathrm{~min}$ & 5,4 & 470 & 324 & 1,40 \\
$20 \mathrm{~min}$ & 8,1 & 520 & 420 & 1,38 \\
$1 \mathrm{~h}$ & 12,3 & 620 & 569 & 1,32 \\
$4 \mathrm{~h}$ & 28,4 & 970 & 1140 & 1,34 \\
$9 \mathrm{~h}$ & 47,3 & 1430 & 1811 & 1,28 \\
$18 \mathrm{~h}$ & 70,7 & 2050 & 2642 & 1,26 \\
$27 \mathrm{~h}$ & 77,2 & 2480 & 2873 & 1,21 \\
\hline
\end{tabular}

I) calibrated with polystyrene standards

2) calc. from $M_{n}=M_{M}([M] /[I]) \cdot C+M_{\text {Head }}+M_{\text {End }}$ 


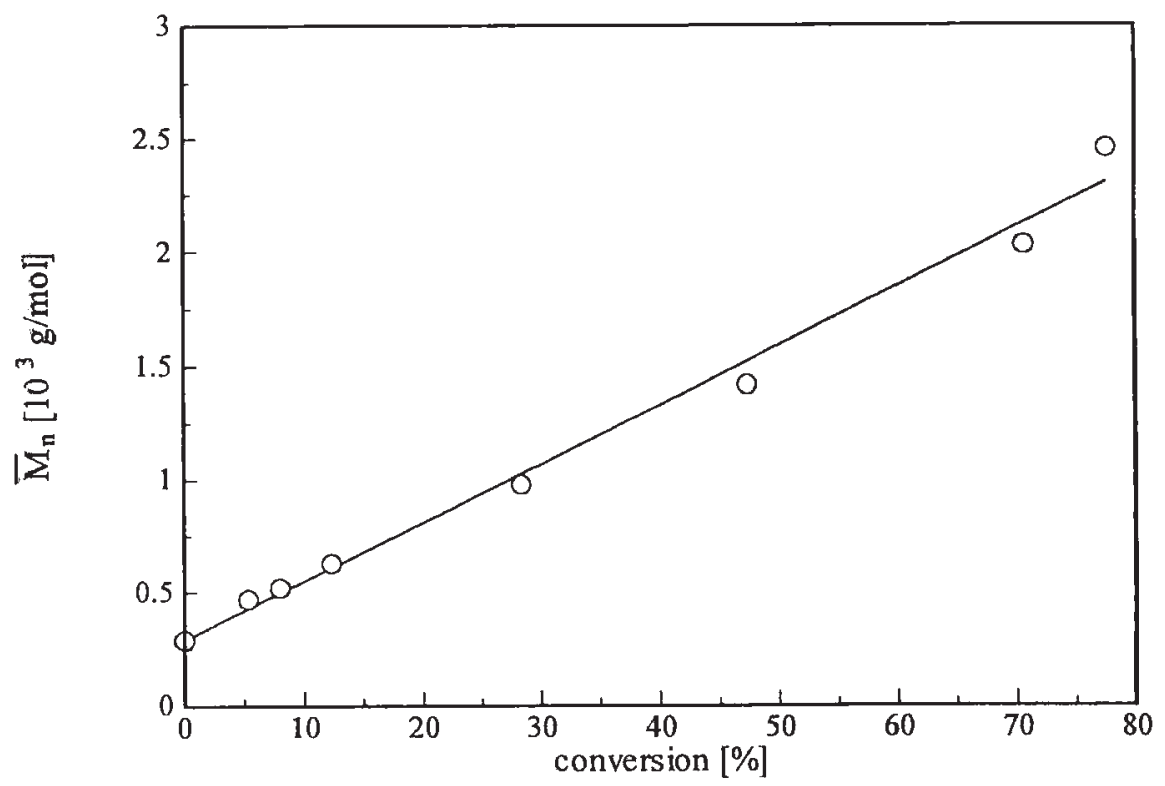

FIG. 4: Plot of molar mass versus conversion for the polymerization of CEVE, initiated by 1-iodo-1(2-methylpropyl-oxy) ethane/(n-Bu) ${ }_{4} \mathrm{NClO}_{4}$ in $\mathrm{CH}_{2} \mathrm{Cl}_{2}$ at $-17^{\circ} \mathrm{C}$.

modifying poly(CEVE) with the anion of pyrrolidone according to the following scheme:
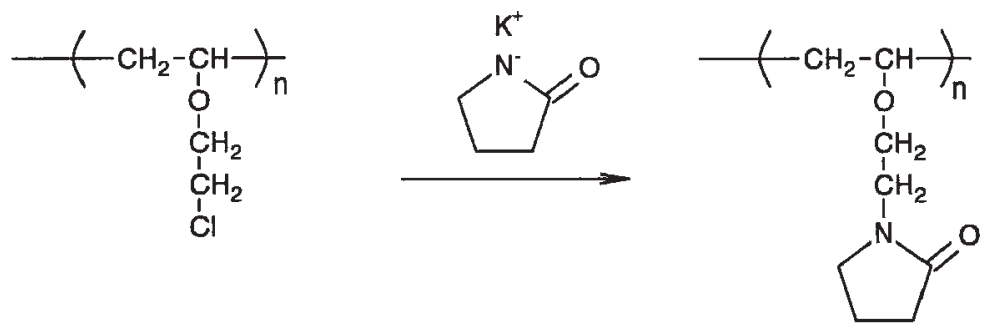

The ${ }^{1} \mathrm{H}$ NMR of the resulting product is shown in FIG. 5 . signals at 2,0 and $2,3 \mathrm{ppm}$ which are absent in 


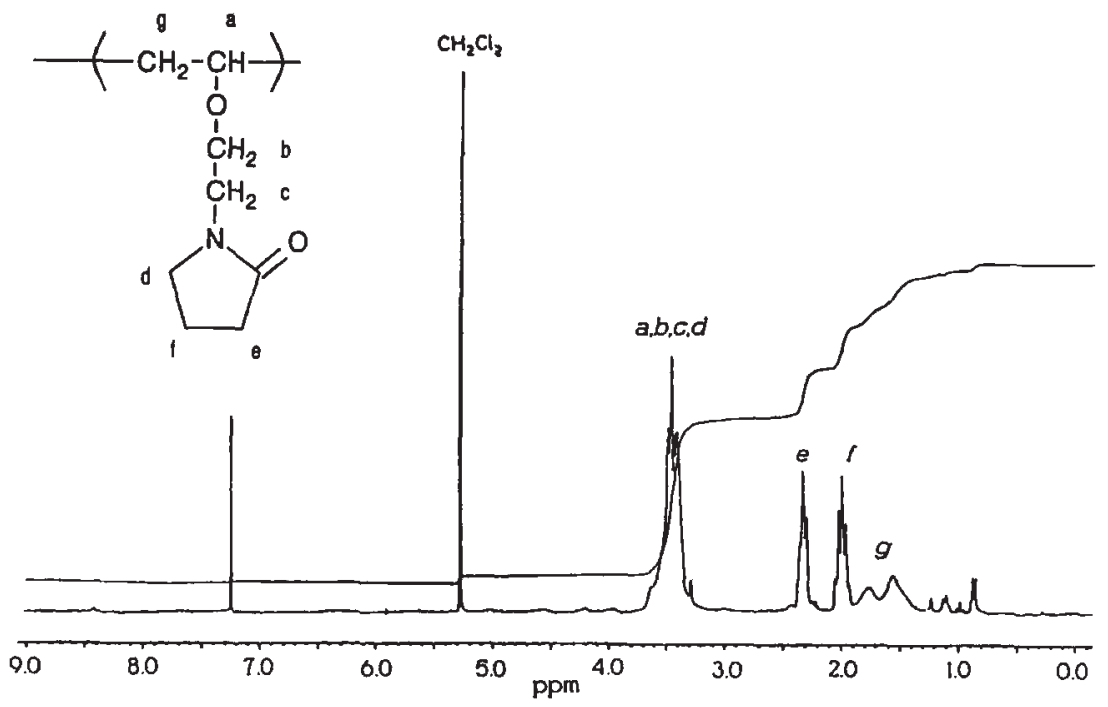

FIG. 5: ${ }^{1} \mathrm{H}$ NMR of poly(2-(1-pyrrolidonyl)ethyl vinylether in $\mathrm{CDCl}_{3}$.

poly (CEVE) belong to the protons $e$, $f$ of the pyrolididone ring. Equation [1] can be used for a quantitative calculation of the degree of substitution.

$$
5 \times I_{\text {CEVE }}=I_{A}-\left(I_{p} / 2\right) \times 7
$$

$I_{\text {CEVE }}=$ Integral of one proton of CEVE

$I_{A}=$ Integral of the region 3,9-3,2 corresponding with 7 protons of a substituted unit $(a, b, c, d)$ and 5 protons of an unsubstituted chlorinated unit $(a, b, c)$

$I_{p}=$ integral over 2 protons of the pyrrolidone ring (the signals at 2.0 or 2,3 representing 2 protons each). 
The calculation revealed that the substitution of the shlorine was $100 \%$. This result is supported by elemental analysis which does not show any residual chlorine. The molar mass of poly (PEVE) according to $\mathrm{GPC}$ (560 $\left.\mathrm{g} \mathrm{mol}^{-1}\right)$ was much lower than the calculated value of $3360 \mathrm{~g} \mathrm{~mol}^{-1}$ (by taking into consideration of the molecular weight of the poly (CEVE) adduct as $M_{n}=2350 \mathrm{~g} \mathrm{~mol}^{-1}$ ). However, we believe that this is due to the higher polarity of the product poly(PEVE) compared with the poly(CEVE) adduct and therefore the elution time is extended. This view is strongly supported by the molar mass determined via ${ }^{1} \mathrm{H}$ NMR : $3240 \mathrm{~g} \mathrm{~mol}^{-1}$ which is close to the calculated value of $3360 \mathrm{~g} \mathrm{~mol}^{-1}$.

\section{EXPERIMENTAL PART}

\section{INSTRUMENTS}

IR: Digilab FTS-40 (FT-IR); ${ }^{1} \mathrm{H}$ NMR: Bruker AC 250 (250 $\mathrm{MHz}) ;{ }^{13} \mathrm{C}$ NMR: Bruker AC $250(62,5 \mathrm{MHz}) ;$ GPC: Waters 510, Waters $590 \mathrm{RI}$, THF; DSC: Perkin Elmer DSC 7; GC: Varian GC 3700, column CP Sil 5CB; Cryostate: Lauda UK 8 DW.

\section{CHEMICALS}

Solvents were dried and freshly distilled before use. Isobutylvinylether (Fluka) and 2-chloroethyl vinylether (Fluka) were dried over $\mathrm{CaH}_{2}$ and freshly distilled before use. Tetrabutylammonium perchlorate (Fluka) was dried for $24 \mathrm{hrs}$ under high vacuum conditions and stored under argon. 1-Iodo-1-(2-methylpropyl-oxy) ethane was synthesized as described in the literature ${ }^{7}$.

Poly (CEVE)

The polymerization of 2-chloroethyl vinylether (CEVE) was carried out in methylene chloride under argon at $-10^{\circ} \mathrm{C}$ in the presence of xylene as internal standard (for 
quant. determination of conversion by GC) . 1-Iodo-1-(2methylpropyl-oxy) ethane and (n-Bu) ${ }_{4} \mathrm{NClO}_{4}$ (see Table 1) were added to CEVE to initiate the polymerization. After complete conversion of CEVE the polymerization was quenched with methanol/aqu. $\mathrm{NH}_{3}$. The polymer solution was then washed with $\mathrm{Na}_{2} \mathrm{~S}_{2} \mathrm{O}_{3}$ (10\% solution in water) and with water. The solution was dried over sodium sulfate. Then the solvent was removed in vacuum and the residue was redissolved in toluene. Insoluble salts were filtered off. After removal of the solvent the polymer was dried in vacuum and characterized.
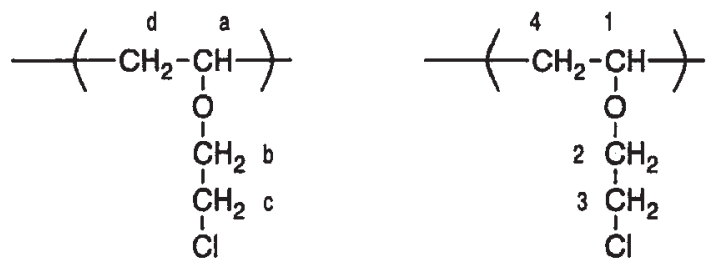

${ }^{1} \mathrm{H} \quad \mathrm{NMR} \quad\left(\mathrm{CDCl}_{3}\right) \quad \delta(\mathrm{ppm}): 3,9-3,4 \quad\left(\mathrm{H}^{\mathrm{a}}, \mathrm{H}^{\mathrm{b}}, \mathrm{H}^{\mathrm{c}}\right) ; 2,0-1,4 \quad\left(\mathrm{H}^{\mathrm{d}}\right)$

${ }^{13} \mathrm{C}$ NMR $\left(\mathrm{CDCl}_{3}\right) \delta(\mathrm{ppm}): 73,6\left(\mathrm{C}^{1}\right) ; 68,7 \quad\left(\mathrm{C}^{2}\right) ; 43,7 \quad\left(\mathrm{C}^{3}\right)$; $41-39\left(C^{4}\right)$

Poly(2-(1-pyrrolidonyl)ethyl vinylether)

$1,11 \mathrm{~g}$ (13 mmol) pyrrolidone, $0,05 \mathrm{~g}(0,15 \mathrm{mmol}$ ) tetrabutylammoniumbromide and $1,35 \mathrm{~g}$ (12 mmol) potassium $t$-butylate were dissolved in $15 \mathrm{ml}$ dimethylformamide (DMF) and stirred at room temperature for one hour. Then $1 \mathrm{~g}$ of poly (CEVE) $\left(\mathrm{M}_{\mathrm{n}}=2350 \mathrm{~g} \mathrm{~mol}^{-1}\right)$ dissolved in $10 \mathrm{ml}$ toluene was added slowly. This mixture was heated up to $70^{\circ} \mathrm{C}$ and stirred for $16 \mathrm{hrs}$ at this temperature. After cooling to room temperature the mixture was filtered. The precipitate was washed with toluene and DMF. Then the filtrate was dropped into diethylether at $-60^{\circ} \mathrm{C}$. The precipitate was washed several time with cool diethylether $\left(-60^{\circ} \mathrm{C}\right)$, redissolved in a small portion of $\mathrm{CH}_{2} \mathrm{Cl}_{2}$ and $\mathrm{Cleared}$ off by centrifugation. After 
separation of the solvent an oily product was received. Yield: $0,7 \mathrm{~g}(50 \%)$

IR (film) $\mathrm{cm}^{-1}: 2926,2878(\mathrm{CH}) ; 1689,1681$ (CO); 1118, 1097 (COC).
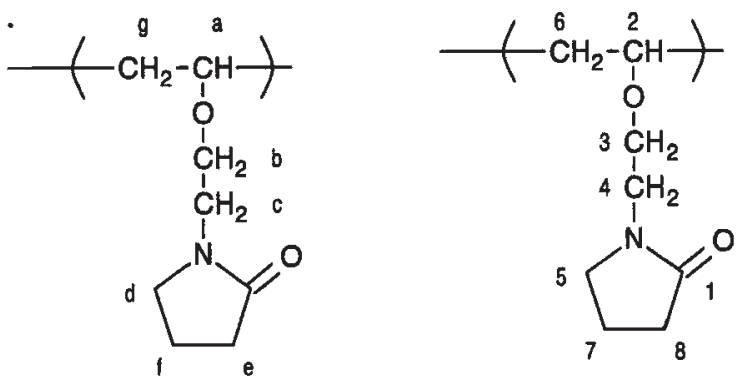

${ }^{1} \mathrm{H} \operatorname{NMR}\left(\mathrm{CDCl}_{3}\right) \delta(\mathrm{ppm}): 3,9-3,3\left(\mathrm{H}^{\mathrm{a}}, \mathrm{H}^{\mathrm{b}}, \mathrm{H}^{\mathrm{c}}, \mathrm{H}^{\mathrm{d}}\right), 2,3\left(\mathrm{H}^{\mathrm{e}}\right)$, $1,95\left(\mathrm{H}^{\mathrm{f}}\right), 1,9-1,4\left(\mathrm{H}^{\mathrm{g}}\right)$

${ }^{13} \mathrm{C} \mathrm{NMR}\left(\mathrm{CDCl}_{3}\right) \delta(\mathrm{ppm}): 174,8\left(\mathrm{C}^{1}\right) ; 73,5\left(\mathrm{C}^{2}\right) ; 65,9\left(\mathrm{C}^{3}\right)$; $48,3\left(C^{4}\right) ; 42,6\left(C^{5}\right) ; 41-38\left(C^{6}\right) ; 30,5\left(C^{7}\right) ; 17,7\left(C^{8}\right)$

Elemental analysis: $(\mathrm{Mn}=3240 \mathrm{~g} / \mathrm{mol}=20$ repeat units + head + end)

calc. $(\%): \quad \mathrm{C}: 61,98 \mathrm{H}: 8,60 \mathrm{~N}: 8,65 \quad 0: 20,76 \mathrm{Cl}^{-}: 0,0$

found: $\quad \mathrm{C}: 60,67 \mathrm{H}: 8,58 \mathrm{~N}: 7,13 \mathrm{O}: 23,53 \mathrm{Cl}^{-}: 0,0$

\section{REFERENCES}

1. T. Hashimoto, H. Ibuki, M. Sawamoto, T. Higashimura, J. Polym. Sci., Polym. Chem. ed. 26, 3361 (1988)

2. V. Heroguez, A. Deffieux, M. Fontanille, Makromol. Chem., Macromol. Symp. 32, 199 (1990)

3. M. Schappacher, A. Deffieux, Macromolecules 24, 2140 (1991)

4. M. Schappacher, A. Deffieux, Macromolecules 24, 4221 (1991)

5. H. Kröner, O. Nuyken to be published, H. Kröner, PhD-Thesis, Bayreuth 1989

6. G. Rieß, PhD.-Thesis, Bayreuth 1993

7. O. Nuyken, H. Kröner, Makromol. Chem. 191, 1 (1990) 